\title{
Fetichismo de las armas y fetichismo de la mercancía: reflexiones sobre la lucha de clases, la política y la guerra \\ Fetichism of weapons and fetichism of commodities: reflections on class struggle, politics and war
}

Felipe Pereyra Rozas

Universidad Nacional de La Plata - Argentina

La Plata, Argentina

felipe.pereyrarozas@presi.unlp.edu.ar

Blas Darío Estevez

Universidad Nacional de La Plata - Argentina

La Plata, Argentina

bestevez@fahce.unlp.edu.a

\section{RESUMEN}

El presente trabajo se propone reflexionar sobre la relación entre guerra y política. El punto de partida de son algunas indicaciones realizadas por Juan Carlos Marín acerca de la necesidad de producir una crítica del fetichismo de las armas presente en las concepciones militaristas del estatuto de la guerra en el marco del capitalismo que sea paralela a la crítica del fetichismo de la mercancía en Marx. Para pensar este paralelismo se toman los conceptos de "estado-nación" y "ciudadano" como las claves de la construcción de la fuerza armada de la burguesía. La "ciudadanización" como proceso de disciplinamiento de los cuerpos fundamental del capitalismo es explorada a partir de dos autores. Por un lado, se retoma a Louis Althusser, quien afirma que en la lucha de clases lo que se enfrentan no son solo dos clases, sino también dos formas de lucha. Por otra parte, se explora esta tesis a partir de los análisis que Dardo Scavino hace del dispositivo sarmientino de la oposición entre "Civilización y Barbarie" como modelo de constitución de la lucha de clases burguesa y proceso de ciudadanización en la Argentina. Por último, en las conclusiones se exploran los límites de la noción de "ciudadano" en el marco de las políticas neoliberales impuestas por las dictaduras latinoamericanas y el dominio del capital financiero en el ultra-imperialismo

Palabras claves: capitalism; cuerpo; democracia, estado; guerra

\section{ABSTRACT}

The aim of this paper is to reflect on the relationship between war and politics. The starting point are some indications made by Juan Carlos Marín about the necessity to produce a criticism on fetichism of weapons that runs in parallel with the criticism made by Marx on the fetichism of commodities. To think this paralelism we use the concepts of nation-state and that of citizen as the keys on the construction of the armed forces of bourgeoisie. The process of construction of citizenship as one of disciplining bodies is thought to be fundamental in capitalism and it is explored in the ideas on class struggle in two authors. On the one hand, Louis Althusser states that in class struggle what we find is not only two classes, but also two forms of struggle. On the other hand, this thesis is developed and explored in the analisis that Dardo Scavino makes of the device "Civilization and Barbarism" putted forward by Sarmiento as a model of the constitution of bourgeoisie's class struggle and constitution of citizenship in Argentina. In the conclusions we explore the notion of "citizen" and it's limits in the frame of neoliberal politics imposed by military dictatorships in latin-america and the hegemony of financial capital in ultra-imperialism.

Keywords: capitalism; body; demcracy, state; war 


\section{Introducción. De la silla a la cabeza}

En el año 1986 el sociólogo argentino Juan Carlos Marín fue convocado por el filósofo Tomás Abraham para debatir sobre la obra de Foucault en el marco de la cátedra que dictaba este último. El debate se editó posteriormente bajo el título de La silla en la cabeza (1987). Las razones de esta elección de título se hallan en el desarrollo mismo de la conversación. Marín, quien lee decididamente a Foucault sobre el trasfondo de Marx, comienza por comentar su asombro por la desaparición de la teoría marxista en la academia de la Argentina post-dictatorial. Si la unión de la teoría marxista y la práctica política proletaria ha sido un verdadero acontecimiento en la historia de las luchas de las clases subalternas, se impone pensar su separación también como un verdadero acontecimiento histórico. Para hacerlo, Marín plantea una pregunta: “ipersonificación de qué relaciones sociales son los desaparecidos?". El sociólogo plantea que la paz que se vive en aquellos años no es el fin de la guerra, sino la victoria del enemigo. Ello supuso como premisa el desarme de las masas por la vía de una reorganización de los cuerpos en el espacio social. Pero no se trata solo de un desarme material, sino también de un desarme intelectual.

Marín acusa al mundo académico de ser condescendiente con este proceso. La conversación va adquiriendo tensión y cuando uno de los interlocutores afirma que los marxistas, al igual que los académicos, "han comido mucha mierda", Marín se exaspera y responde: "Perdón ¿usted se refiere a mí? Porque si se refería a mí le parto una silla en la cabeza". A partir de allí reina en el debate la apoteosis del desconcierto. El posterior desarrollo del intercambio buscará explicar este exabrupto apelando a la aparición de otro lenguaje, diferente del lenguaje teórico-académico: el lenguaje de la acción y de las armas (1987, pp. 107108).

Curiosamente, esta interpretación del suceso, hecha al pasar, hace sistema con una obra anterior de Marín (2009), editada bajo el título de "Cuaderno 8". Porque esta idea de dos lenguajes inconmensurables introduce el problema de dos prácticas cuyo desajuste específico no admite traducción, problema que Marín formula a su modo. Para este autor es necesario criticar a Clausewitz del mismo modo en que Marx lo hizo con la economía política clásica, denunciando la ficción de un espacio homogéneo para los enfrentamientos:

Hay un primer énfasis en Clausewitz: que la guerra es la continuación de la política por otros medios. El medio que él enfatiza es lo que se ha llamado 'las armas'. Pero źquién tiene la capacidad de otorgarle el carácter de arma a una cosa? (2009, p. 67).

Es importante detenerse un momento en esta pregunta. Hay un peligro fundamental en la frase de Clausewitz "la guerra es la continuación de la política por otros medios", y tiene que ver con leer la relación guerra/política como una relación secuencial y polar. Parados en la post-dictadura, cabe preguntar: si en la dictadura la lucha de clases toma la forma de una guerra abierta ¿acaso la democracia es el fin de la guerra y el comienzo de la política? Es posible entonces ceder a la tentación de invertir el apotegma: "la política es la continuación de la guerra por otros medios", por eso la democracia es la democracia de la derrota.

Pero esta inversión no parece convincente. Si se acepta que la política es la continuación de la guerra por otros medios, entonces los ciudadanos deberían ocupar el lugar de los Estados en guerra. Se podría objetar que por esta vía no se hace más que pensar la guerra bajo un modelo jurídico, que replica al nivel de los ciudadanos lo mismo que sucede entre los Estados. El inconveniente salta a la vista: tomando la soberanía en términos hobbesianos, se debe notar que mientras los Estados no reconocen un derecho superior, los ciudadanos solo se constituyen como tales al volverse sujetos de un Estado de derecho.

Replicar el modelo del duelo al nivel de la política democrática lleva a darle a la lucha de clases la forma policiaca del enfrentamiento entre la justicia y el delito, porque en el universo homogéneo de la ideología jurídica burguesa lo único que se encuentra arriba de la política es la ley, y lo que cae fuera de la ley no es inteligible como política: de allí que se pueda verificar, en la post-dictadura, un proceso en el cual la violencia tiende cada vez más a identificarse con formas despolitizadas como la "inseguridad" o el narcotráfico, pero no con la constitución de una fuerza armada de masas. El enemigo deja de ser la "subversión" y pasa a serlo la "delincuencia". 
Otra manera de interpretar la inversión del apotegma de Clausewitz podría ser la siguiente: la política es la continuación de la guerra por otros medios porque la guerra es la verdad de la política, la democracia es apenas una ilusión que encubre un enfrentamiento armado que puja por salir a la superficie y hacerse consciente. Pero los problemas reaparecen: jamás suena la hora solitaria de la última instancia. Es decir que las clases no se enfrentan en su desnudez, como si fueran dos conciencias exteriores. Si así fuera jamás se comprendería como la ideología de la clase dominante (en este caso, la ideología jurídica) puede volverse la ideología dominante.

Para explicar el fenómeno de la dominancia de la ideología dominante al interior del paradigma de la conciencia los caminos se bifurcan: o bien se comprende la estrategia como el producto de una teleología de la conciencia, o bien se niega la posibilidad de una estrategia por la radical opacidad de la conciencia.

En el primer caso, el modelo del duelo sobre terreno homogéneo se repite, puesto que la contradicción capital-trabajo, burguesía-proletariado, aparece como una contradicción simple entre dos términos homogéneos de polaridad opuesta, como dos voluntades diáfanas de dos Sujetos con objetivos contrapuestos, donde uno personifica la parcialidad y el otro la universalidad. Esta épica por la justicia histórica tiene la misma estructura teleológica que el relato heroico de una supuesta "república perdida", interrumpida por los diferentes golpes militares y siempre recuperada: porque la república es el origen y el destino, solo que en este caso se ubica allí el comunismo.

En el segundo caso, para esquivar a una idea de conciencia supuestamente perimida para nuestro presente filosófico, habrá que apelar a hipótesis subsidiarias como la idea de una servidumbre voluntaria o un deseo de sumisión primordial en el sujeto: una predisposición afectiva a ser dominado, o al menos una ambivalencia. Estas valencias afectivas que se encierran en la descripción del estado de cosas que resulta de la dominación no se presta tanto a la explicación. Apenas podrá esta opción teórica reponernos del espanto de ver a las clases populares elegir mediante el voto a gobiernos de derecha y de abierta tendencia fascista. Sin negar la necesidad de una teoría de los procesos de subjetivación/sujeción, se notará inmediatamente que el espacio teórico que queda vacío por la desaparición de conceptos como contradicción o lucha de clases se vuelve objeto de disputa para la reintroducción de una concepción jurídica del poder que puede muy bien soportar la idea de una opacidad primordial en el sujeto.

Si ninguna de estas alternativas es satisfactoria es, simplemente, porque la relación política/guerra no puede pensarse como una relación secuencial, como si una reemplazara a la otra, pero ambas se excluyeran. Tampoco sus elementos pueden comprenderse en términos homogéneos y polares, como si la contradicción entre clases fuera una contradicción lógica que contrapone A y no-A. Para Marín, en la lucha de clases lo que se enfrentan no son sujetos, ya sea que los concibamos en términos de ciudadanos o clases con atributos de sujeto. En el enfrentamiento lo que se encuentra son "fuerzas sociales". Éstas se constituyen en una serie compleja de articulaciones entre prácticas, y Marín le otorga un lugar especial entre ellas a la "teoría” y a la "lucha teórica", de la cual nos da una definición:

La lucha teórica hace referencia a los enfrentamientos que se producen entre las distintas facciones sociales, para el logro de una estrategia que permita la redefinición de las condiciones del régimen imperante (2009, p. 39)

Partiendo de esta definición y su funcionamiento, es posible ver en la palabra "teoría" como la usa Marín al menos tres elementos: ciencia, ideología y filosofía. Ciencia, puesto que Marín apunta a la idea de una estrategia posibilitada por el conocimiento de la trayectoria de los encuentros entre fuerzas que conduce a la reproducción o transformación de las relaciones dominantes de un territorio. Ideología, puesto que las fuerzas sociales en el enfrentamiento se constituyen por una serie compleja de formas de subjetivación, pero también porque en la teoría se disputa la dirección (revolucionaria o no) de las fuerzas sociales en pugna. Y filosofía, puesto que hacer teoría implica intervenir en la teoría desde una posición de clase.

Por eso, porque se trata de una intervención, no solo interesan sus palabras, sino también su gesto: la silla anida en un umbral. El gesto de Marín, su exabrupto, tiene una significación filosófica porque permite apresar la aparición en el pensamiento de un exterior del pensamiento, de un afuera constitutivo que el pensamiento lleva en su interior en el modo de una condición y por tanto de algo no-enunciable. La silla 
no es un objeto filosófico, porque es mudo. Tampoco un objeto cotidiano, porque se introduce en el universo filosófico como un exterior inesperado. Al mismo tiempo no es del todo un arma. Pero retomemos entonces la pregunta que planteamos más arriba “¿quién tiene la capacidad de otorgarle el carácter de arma a una cosa?"

Sobre la base de esta pregunta, en el presente trabajo nos proponemos, primero, explorar el paralelo entre el fetichismo de las mercancías y el fetichismo de las armas tal como lo plantea Marín. De este paralelo esperamos obtener herramientas teóricas para pensar la lucha de clases fuera de la concepción jurídica de la guerra y el enfrentamiento, fundamentalmente a partir de la noción de "ciudadanización". Para ello retomaremos algunas tesis críticas de Althusser, principalmente la idea de que en la lucha de clases lo que se enfrenta no son clases, sino dos formas de lucha. Buscaremos ilustrar esta idea a partir de los análisis de Scavino, situándonos en uno de los dispositivos de subjetivación fundamentales para la constitución del estado-nación argentino: el par sarmientino Civilización/Barbarie. Para finalizar propondremos algunas hipótesis extraídas de Balibar sobre el neoliberalismo y sus formas de sujeción/subjetivación en el marco del ultra-imperialismo para poner a prueba los límites de la noción de ciudadano.

\section{Fetichismo de la mercancía y fetichismo de las armas \\ 2.1 El fetichismo de la mercancía y la lucha de clases}

Marín plantea que "así como se produjo la crisis del fetichismo de la mercancía es necesario producir la crisis del fetichismo de las armas" (2009, p. 68). El paralelo entre una teoría de la guerra y la teoría marxista de la historia es llamativo ¿en qué medida puede justificarse? Cuando se formula la pregunta cómo puede constituirse un arma se parte del supuesto de que pueden ser constituidas como tales, de que no llegan caminando solas hasta nosotros. Marx tampoco cedía al empirismo sobre este punto. En Trabajo asalariado y capital se pregunta:

\footnotetext{
¿Qué es un esclavo negro? Un hombre de la raza negra. Una explicación vale tanto como la otra. Un negro es un negro. Sólo en determinadas condiciones se convierte en esclavo. Una máquina de hilar algodón es una máquina para hilar algodón. Sólo en determinadas condiciones se convierte en capital. Arrancada de estas condiciones, no tiene nada de capital, de mismo modo que el oro no es de por sí dinero, ni el azúcar el precio del azúcar. (Marx, 1975, p. 36)
}

¿Qué es lo que hace de un individuo concreto un trabajador libre, un agente de la represión o un capitalista? ¿Qué hace de una mujer una madre, una sujeta de derechos o una prostituta? Ciertas condiciones, o, mejor dicho, determinadas relaciones sociales. Con las mercancías sucede lo mismo: son constituidas por determinadas relaciones sociales.

En el ámbito de la circulación, del intercambio de mercancías, si se pregunta cómo es posible conmensurar dos valores de uso irreductibles, se responderá que el valor es el denominador común que nos permite hablar de intercambios de equivalentes. Claro que cuando se dirige la mirada a la compraventa de fuerza de trabajo esta explicación muestra su límite: si el salario equivale a la fuerza de trabajo, entonces jamás se podrá comprender de dónde surge el plusvalor. Por eso se ve la necesidad de dirigirse hacia otras esferas, fuera de la circulación, para comprender que la forma jurídica del intercambio entre propietarios de mercancías es una evidencia ideológica, pero no ilusoria, sino material, porque es sustancial al proceso de explotación que se da en la esfera de la producción.

Nótese un elemento fundamental: para Marx, los efectos ilusorios del fetichismo son absolutamente objetivos y materiales. No basta con una "toma de conciencia" para disiparlos, puesto que es en tanto que los individuos encarnan las categorías ideológicas que organizan lo "económico" que llegan a tomar "conciencia" de sujetos. En efecto, las categorías centrales de la ideología burguesa "personas" y "cosas" aparecen como las evidencias primeras en el terreno del intercambio. Pero se debe indagar si ellas son las categorías que el materialismo histórico utiliza como algo a fundamentar o como punto de partida para el análisis científico.

Como lo hace notar Balibar (1976), el proceso de exposición de El capital parte de una constatación cuyo estatuto no es el del origen de un desarrollo necesario, sino que comienza por el modo en que la instancia 
económica de una formación capitalista aparece. Ésta aparece como un "inmenso arsenal de mercancías" cuya forma elemental es la forma-mercancía. Pero para tomar dicha forma como elemental, como origen del conocimiento, es necesario hacer una doble abstracción (Balibar, 1976, p. 226). Por un lado, abstracción del proceso que lleva a la generalización de la mercancía como forma de la riqueza, es decir, del proceso histórico que lleva a la universalidad (o, al menos, dominancia) de la producción de mercancías. Por el otro, es necesario hacer abstracción de los elementos "superestructurales" o "ideológicos" que hacen posible que lo económico aparezca como el conjunto de relaciones entre propietarios-cambistas jurídicamente iguales. Es decir que, la apariencia de la mercancía como forma elemental de la "riqueza" (concepto también ideológico), es una apariencia para individuos históricamente constituidos como propietarios libres, proceso que requiere de la intervención de una multiplicidad de aparatos ideológicos, de la ideología jurídica y de la ideología económica:

\begin{abstract}
....se trata de una apariencia que no reside en las simples representaciones individuales en que se materializa cotidianamente, pero ante todo en las formas sociales institucionalizadas del derecho, la ideología jurídica y económica que invisten las prácticas cotidianas del cambio de mercancías (y de la fuerza de trabajo como mercancía particular). Como sabemos, no hay cambio entre valores equivalentes sin contrato entre propietarios iguales y legítimos; pero no hay contrato sin “acuerdo de las voluntades", y, por tanto, sin representación ideológica de la persona y de su libre capacidad de disposición de las cosas. Lo que aquí ha sido presupuesto es, por tanto, la presencia y la eficacia de los elementos de la superestructura jurídica e ideológica, directamente implicadas en el proceso de cambio y, más generalmente, en el proceso de circulación de mercancías (Balibar, 1976, p. 229).
\end{abstract}

Del mismo modo, las abstracciones como "personas" y "cosas" forman parte de lo real, pero de lo real ideológico, de cuya crítica puede obtenerse el conocimiento de la instancia económica capitalista, como sucede a lo largo de El Capital. Esto significa que la mercancía y el sujeto libre son aquellas evidencias con las que es necesario romper para poder conocer algo de ellas. Lo que Marx se pregunta no es, como lo haría la concepción jurídica del conocimiento “¿Cuáles son las condiciones de posibilidad de lo "económico”?" Es decir, siendo que lo "económico" es lo dado, pues al nivel de lo vivido es una evidencia total que los sujetos contratan entre ellos para apropiarse de la naturaleza, la concepción jurídica se preguntaría por las condiciones de posibilidad de esa evidencia y se remontaría hasta el sujeto jurídico. Marx, por el contrario, se pregunta cuáles son las condiciones materiales (es decir, históricas) que estructuran las evidencias de "lo económico" y que, por tanto, son la condición material de su realización.

Si los intercambios son posibles, la causa no es que el valor sea una sustancia subyacente o que todos posean el mismo concepto de valor en sus cabezas. Su "validez" es interior a la práctica del intercambio de mercancías, cuya generalización tiene una serie de premisas históricas: la constitución del trabajador libre (su separación de los medios de producción y del producto del trabajo) y la constitución en la ideología jurídica del sujeto de derecho (que divide el mundo entre personas y cosas, mediadas por relaciones de propiedad/no propiedad). Pero también depende de la reproducción de las premisas de dicha práctica, con lo cual se ven una serie de relaciones de fuerza conduciendo a la separación del trabajador y los medios de producción, a la vez que a su unión en el proceso de trabajo. Este flujo de reunión y separación, cuya lógica es pasible de análisis, es la trama de esas relaciones de fuerza.

Entonces un concepto denso y de tan larga historia como el de forma debe ser repensado como el efecto de una serie de relaciones de fuerza que organizan un flujo y cuya persistencia no es otra que la de su constante insistencia por permanecer en la existencia: esa insistencia condensa en abstracciones que organizan las relaciones de fuerza. En el fetichismo de la mercancía nos preguntamos acerca del valor como abstracción material e histórica. La pregunta crítica de Marx toma entonces la siguiente forma ibajo qué necesidad la contradicción de clase toma la forma de la identidad entre los individuos? La respuesta obliga a dirigirse al proceso histórico de constitución del trabajador libre por una serie de prácticas de desposesión y a las luchas de poder. Las formas de esta desposesión, que en última instancia es una guerra, puede ser un cívico contrato salarial. La cuestión reside en explicar la necesidad que le confiere una forma u otra: las formas pacíficas de expropiación solo pueden comprenderse si previamente se comprende el proceso de desposesión del poder de los cuerpos. 


\subsection{El fetichismo de las armas y su crítica}

En el caso de las armas, Marín propone un modelo similar. No implica esto que las armas sean como las mercancías. Implica que, para la constitución de una teoría de la guerra que tome en cuenta el concepto central de lucha de clases, se debe escapar al empirismo:

Lo sustantivo es tener un cuerpo teórico que nos permita percibir: cuáles son esas relaciones sociales que tienen la capacidad de transformar cierto campo material en los medios, las armas, necesarias para cierto enfrentamiento. Es el carácter social el que transforma esas cosas materiales (Marín, 2009, p. 68).

Criticar a Clausewitz del mismo modo que Marx criticó a la economía política clásica implica dirigirle la pregunta por la constitución de las fuerzas armadas que toma como un dato: así como los sujetos libres no son un dato, sino un punto de llegada para la explicación, del mismo modo las armas y las fuerzas armadas son un punto de llegada.

El concepto fundamental a este respecto es el de fuerza social. Así como los individuos solo pueden ser agentes de la práctica económica bajo determinada forma-sujeto, es decir, como personificación de una categoría que se define en el modo de producción que domina la formación social en la que tiene su existencia histórica, del mismo modo una fuerza material, armada, debe pensarse como producto del proceso de constitución de una fuerza social. Este es un modo de afirmar la primacía de la política sobre la guerra. Para Marín esta primacía puede leerse en la construcción histórica del ciudadano: “la ciudadanía podría ser leída como el proceso de constitución o de formación del poder de la burguesía. Es el eje que ocupa casi el mismo status que la noción de mercancía en una teoría del capital” (2009, p. 66). El ciudadano, como sujeto de derecho, átomo último de lo social ocupa, según Marín, “casi” el mismo status que la mercancía: es decir, primera evidencia, pero también efecto ideológico. Punto de partida para la percepción, pero punto de llegada para la explicación.

Es en este sentido que se puede decir que en la lucha de clases no se enfrentan sujetos. Tampoco las clases como sujeto. Sino las clases constituidas como fuerzas sociales. Pero ¿qué implica representarse a las clases como sujetos? Supondría concebirlas como dos cuerpos externos, cuyas conciencias y voluntades se contraponen porque preexisten la una a la otra.

Para escapar a esta concepción jurídica de las clases y la lucha de clases, la tesis marxiana según la cual "la lucha de clases es el motor de la historia" debe leerse como una tesis histórica y no ontológica ¿En qué sentido? Las formas de la lucha de clases son las que definen los elementos en pugna, y no a la inversa. Pero en una sociedad de clases, dividida en clases, lo que hay es una forma específica de no-posesión. En el capitalismo se encuentran formaciones sociales que deben reproducir las formas de no-posesión de la fuerza de trabajo, de los medios de producción y del producto, por parte de la clase de los productores inmediatos, es decir, la clase trabajadora.

Esta forma de no-posesión es la que debe reproducirse, no negativamente, como si la clase trabajadora existiera antes de esta desposesión. Es bajo las formas de reproducción de la no-posesión por las que se existe la lucha de clases que define a las clases de manera inmanente a este proceso mismo. Esta idea de una relación inmanente entre la norma que rige el enfrentamiento y los elementos en pugna se encuentra en Althusser, para quien las clases no preexisten a su encuentro: en la lucha de clases, la lucha tiene primacía sobre las clases. No sucede que primero existen las clases y luego se enfrentan, sino que la forma específica de su enfrentamiento es lo que las constituye como tales. Pero Althusser agrega un elemento más:

...es necesario concebir la lucha de clases como una lucha que no puede reducirse a la lucha de clase política e ideológica, en consecuencia, a la lucha de clases que puede reivindicar, en la representación ideológica dominante, es decir burguesa, los atributos de la conciencia y la decisión. La lucha de clases debe concebirse como un enfrentamiento de dos luchas de clases (este es el caso: la lucha de clases no es la lucha de dos clases que lucharían la una contra la otra porque son clases, sino la lucha entre dos luchas, la confrontación de dos cuerpos que están ambos en lucha y luchando cada uno con sus propias armas, que en 
absoluto son las mismas en el caso que nos ocupa, las armas de la lucha de clases proletaria no tienen absolutamente nada que ver con las armas de la lucha de clases burguesa, tampoco su estrategia, sus tácticas y su práctica de la lucha), y a partir del dominio de la infraestructura (la explotación), también es necesario concebir que las luchas políticas e ideológicas no son luchas de ideas (porque la idea se refiere al sujeto), porque la ideología, que con demasiada frecuencia se reduce a la política, no son las ideas, sino las prácticas en los Aparatos (Althusser, 2019, pp. 158-159. Énfasis agregado).

Esta indicación resulta interesante y a la vez problemática: "la lucha de clases debe concebirse como un enfrentamiento de dos luchas de clases". Por un lado, esta idea permite notar que la estrategia que las clases ponen en juego en su encuentro no es una estrategia abstracta, es decir, no es simplemente la consecución de un fin. Si así fuera, solo se estaría traduciendo la concepción teleológica que acompaña a la idea de sujeto jurídico al nivel de las clases, como si fueran "sujetos grandes". Para salir de esta concepción, Althusser afirma que se debe pensar que en la lucha lo que aparece son dos formas de guerra. Pero ¿qué puede implicar esto? Para intentar dar una respuesta a esta cuestión se volverá a la constitución del ciudadano como fuerza social de la burguesía.

\subsection{Disciplinamiento y ciudadanización}

Marín afirma que con Marx es posible encontrarse en vías de la constitución de una teoría del poder a partir del momento en que se le otorga un estatuto teórico al cuerpo. La expropiación del poder de los cuerpos, que en la economía remite al proceso de explotación, en la política dirige al problema de la guerra. Las condiciones de existencia de lo corporal, la forma de reproducción de su disposición en el territorio (en un sentido social y no solo geográfico), es el aspecto a analizar. Por su parte, Clausewitz se mantiene en una concepción ideológica de la guerra al tomar las fuerzas armadas que se enfrentan en el combate de manera acrítica, sin preguntarse por las relaciones que le imponen la forma de armas. Sin embargo, hay una distinción que Marín encuentra potente y que puede ser la piedra de toque para desarrollar una teoría de la relación entre política y guerra: la distinción entre fuerzas materiales y fuerzas morales. Las fuerzas materiales remiten al aspecto puramente militar, técnico de una fuerza armada. Pero las fuerzas armadas no se agotan en este aspecto técnico, sino que suponen las fuerzas morales:

\footnotetext{
¿Qué elementos tienen estas fuerzas morales? Las (armas) fuerzas materiales de las (fuerzas) armas morales son los cuerpos. Esta concepción es de gran importancia, porque constituye el 'comienzo' del puente entre la política y la guerra. Pero no es cierto que los cuerpos en cualquier condición sean armas que den fuerza material; tienen que darse ciertas condiciones para que los cuerpos den fuerza material a esas fuerzas sociales. (Clausewitz, 2009, p. 84)
}

Las fuerzas morales son pensadas por Marín en términos de disciplinamiento de los cuerpos. Este disciplinamiento comparte un terreno común con los procesos de explotación que Marx describe. Para que los cuerpos puedan ser expropiados de su fuerza de trabajo, es decir, para que la fuerza de trabajo aparezca como una mercancía entre otras y pueda tener lugar la forma-salario que caracteriza al capitalismo, este disciplinamiento como desposesión y organización de los cuerpos en el espacio social ya tiene que haber tenido lugar. En el caso de la constitución de las fuerzas sociales de la burguesía también hay un proceso de disciplinamiento de los cuerpos.

Marín entiende que el ciudadano es la forma que adquiere el producto de este disciplinamiento y tiene por resultado la fuerza armada de la burguesía, que es la organización burocrática del soldado-ciudadano: "la ciudadanización forma parte del proceso expropiatorio de los cuerpos" (2009, p. 86). Esta ciudadanización debe comprenderse como el conjunto y el efecto de una serie de tecnologías de organización de los cuerpos que tiene una historia específica para cada formación social capitalista. En este sentido, la formación del estado-nación y la ciudadanización aparecen como proceso vinculados, los cuales deben ser pensados para teorizar la articulación entre guerra y política. 
Una indicación de Althusser resulta interesante a este respecto:

\begin{abstract}
¿Por qué las formaciones sociales capitalistas "existen" bajo la forma-nación? Porque, en última instancia -y todo lo demás le está subordinado, por contradictorio que pueda ser-, la forma-nación está impuesta por la existencia del mercado, área geográfica de existencia y desarrollo de la producción mercantil capitalista: no sólo el mercado de productos manufacturados (mercancías), sino también el mercado de medios de producción y también el mercado de la fuerza de trabajo. Este es el punto de partida obligado, y no solo el punto de partida, sino la base material necesaria, inscrita en el espacio geográfico de toda la formación social capitalista (Althusser, 2019, p.166).
\end{abstract}

La historia de las formaciones sociales, indica Althusser, suele pensarse sobre la base del hecho consumado, es decir, a partir de los modos de producción que sí han podido llegar a existir. Pero por esta vía se deja de lado las formas de no-existencia: el secreto de las formas de existencia, es decir, de la forma específica de reproducción de una formación social, se encuentra en su forma de no existencia. El capitalismo, en este sentido, ha debido morir varias veces antes de encontrar su forma de existencia específica. En la Italia del siglo XIV, por ejemplo, el capitalismo no llega a tomar consistencia pese a contar con un nivel de producción industrial que, según Althusser, podría haber permitido su existencia desde una perspectiva técnica. Maquiavelo tuvo que pensar en el vacío para comprender que lo que hacía falta era la forma-nación. Decimos "en el vacío" porque tuvo que pensar esto en un momento en que los estados-nación no existían y debían ser "creados", del mismo modo que para Marín "el soldado-ciudadano es la construcción histórica de la burguesía, es un invento de la revolución política de la burguesía" (2009, p. 86). Tanto la forma-nación como la forma-ciudadano se encuentran impuestas por la necesidad de constituir el mercado en el cual el capitalismo pueda desarrollar la forma de reproducción ampliada que lo caracteriza. A continuación, se observa este proceso en el caso de la Argentina.

\title{
3. Civilización y barbarie ¿dos formas de guerra?
}

Sarmiento dio la forma paradigmática al problema de la unidad nacional en lo que ahora es Argentina, forma que se cifra en unas pocas palabras: on ne tue point les ideés. Cita falsa (y mal escrita), extrae parte de su eficacia de la exhibición de una supuesta cultura letrada que no es más que un dispositivo. Piglia, hace una arqueología casi kafkiana de esta frase:

La cita más famosa del libro, que Sarmiento atribuye a Fortoul es, según Groussac, de Volney. Pero otro francés, Paul Verdevoye, ha venido a decir que tampoco Groussac tiene razón: después de señalar que la cita no aparece en la obra de Fortoul, pero tampoco de Volney, la encuentra en Diderot: On ne tire pas de coups de fusil aux des idées. (1980, p. 17)

Originalmente un grafiti que Sarmiento deja como jeroglífico y una burla en los baños de Zonda, en momentos de su partida al exilio en Chile, esta cita y su traducción aparecen como epígrafe a la edición de 1845 del Facundo, pero no sin cierto desplazamiento: "A los hombres se los degüella, a las ideas no". Esta frase concentra, para Dardo Scavino, toda una concepción de la guerra y la política. Nótese el desplazamiento que se produce en la traducción de la cita de Diderot cuando se vierte al español: el degüello, la ablación de un miembro del cuerpo, forma bárbara de la guerra, no se opone a las "ideas" como ámbito de la persuasión y el debate ciudadano, sino al fusil como símbolo del disciplinamiento del cuerpo a través de la tecnología militar civilizada. La relación que Sarmiento establece entre Civilización y Barbarie no es la de una oposición entre la guerra disolvente en las postrimerías de la revolución independentista y la política como terreno del acuerdo pacífico entre ciudadanos. Lo que se opone en el par Civilización/Barbarie son dos formas de guerra; la conjunción "y" indica una guerra entre formas de la guerra:

...esta guerra no es sólo un enfrentamiento polar entre dos contendientes: es, más que nada, entre dos formas tácticas y estratégicas de hacer la guerra. Esto quiere decir: sus objetivos políticos, sus propósitos militares y sus medios armados varían de uno a otro bando (Scavino, 1993, p. 11). 
Civilización y Barbarie es, más allá del Facundo como texto, un verdadero dispositivo teórico-político del cual Scavino hace una reconstrucción deslumbrante. Al designar el sintagma "Civilización y Barbarie" como un dispositivo se quiere decir que se trata de un mecanismo material de producción de formas de subjetividad. En el caso que se aborda, esta forma no es otra que la del ciudadano. Es decir que se trata de un dispositivo que produce la ciudadanización por la vía de la extensión de la lógica de la guerra al ámbito de la política. Desde la óptica de Sarmiento, Rosas practicaba la política como si fuera la continuación de la guerra por los mismos medios, puesto que aquel buscaba imponer su voluntad a la población por la vía del terror, de un terror sangriento y espectacular cuyas armas son el degüello y la mazorca. ' Sarmiento, por su parte, no produce su dispositivo con el objeto de hacer la guerra a la población mediante una fuerza militar, sino que busca extender la forma militar como medio para disciplinar los cuerpos: "la política sarmientina, lejos de ser una paulatina desmilitarización del Estado, extiende la militarización a todas las combinaciones intra o inter-corporales de la vida social: una permanente e incruenta guerra sin combate" (Scavino, 1993, p. 21).

Retomando la distinción de Clausewitz entre objetivo político y propósito militar, Scavino propone leer el dispositivo sarmientino como una nueva relación entre el estado de guerra y la guerra de Estado. Mientras que Rosas, la Barbarie, no tendría otro objetivo político que el de imponer su voluntad personal mediante una milicia también personal, de manera que no hay una distinción entre el objetivo político y el propósito militar, Sarmiento construye el objetivo civilizatorio como una guerra contra la guerra: el objetivo político es el de producir la Organización Nacional, el cual subordina al propósito militar, que se convierte solo en un medio. El propósito de la guerra de Estado es acabar con la guerra de intereses para convertir el estado de guerra en un comercio: producir la transición de la oposición de intereses y la aniquilación mutua al gobierno de los flujos de los cuerpos por el comercio. El propósito militar de la guerra de Estado no es aniquilar al enemigo, sino desarmarlo, es decir, desposeerlo de sus medios y desarticular sus formas de posesión del suelo. Gobernar sería, en este sentido civilizatorio que Sarmiento le imprime, administrar el movimiento extendiendo la militarización por el disciplinamiento del cuerpo y su organización en el espacio.

Los gauchos que habían sido armados en la guerra de la independencia y que pasan a formar las montoneras, deben ser desarmados en la paz. Pero esta paz implica imponerles a esos cuerpos los códigos de la guerra civilizada. Desarmar al gaucho supone desposeerlo de sus mayores armas. Por un lado, desposeerlo del caballo, porque implica una economía del derroche ejemplificada en la táctica del choque desordenado y porque, a diferencia de la experiencia europea, la caballería formaba parte de las armas populares. La fusilería como arma civilizada, por el contrario, supone toda una economía de movimientos y cierta higiene del enfrentamiento.

Pero el arma fundamental del caudillo, la guarida del gaucho, es sobre todo la extensión. Alberdi también lo había notado:

\footnotetext{
....si el caudillo es una expresión necesaria y útil de la vida pastoral tal como hoy existe, no hay más remedio de acabarlo -según el sistema de Facundo- que concluir con el desierto, con las distancias, con el aislamiento material, con la nulidad industrial, que hacen existir al caudillo como su correlato lógico y normal (Alberdi citado en Scavino, 1993, p. 39).
}

Ahora bien, Scavino entiende que, si la extensión es un problema para Sarmiento, no es por la dimensión del espacio, sino por la relación espacio-tiempo: la gran extensión desconectada del territorio impide la mercantilización porque agobia la velocidad en las transacciones, anula el flujo de mercancías. El gaucho encuentra en la pampa todo lo que necesita, y su actividad no puede convertirse en trabajo; el territorio no puede convertirse en tierras ni proveer de rentas; el comercio no se desarrolla y los intercambios no pueden fiscalizarse ni someterse al poder del Estado: 
La tensión bélica se organiza en torno al modo de ocupación de los suelos, entre dos tipos de poblaciones, entre dos estrategias y dos tácticas. No hay combate sin lucha económica, y esto es tanto más cierto para Sarmiento que para ningún otro autor. De ahí la importancia de conocer la estrategia del vencedor para comprender la paz que administrará: toda economía, en este sentido, es una economía de guerra (Scavino, 1993, p. 52).

Si Clausewitz había comprendido que el territorio es una de las armas fundamentales, determinantes en un enfrentamiento, Sarmiento comprende la determinación en última instancia del territorio por la política. Mientras que la extensión atávica, fragmentada, lenta e impenetrable es la guarida de la Barbarie, la Civilización centra su vía de ataque en la penetración del territorio por el transporte. Los ríos, los barcos, las vías y los ferrocarriles son los fusiles y las mercancías son las balas. Decir esto no implica desconocer, por ejemplo, que también el exterminio de las poblaciones originarias, como la masacre de los pueblos originarios en la zona del Chaco durante 1872 , han sido consustanciales al proceso civilizatorio en el modo de la guerra cruenta. Pero no es esa la forma teórica por la cual el dispositivo sarmientino impone a la vez que oculta sus formas de la guerra, en las cuales la ciudadanía es la abstracción que domina el proceso. A la lentitud de la Barbarie se opone la velocidad de la Civilización, y para ésta el flujo de los cuerpos es la forma específica de imponer la modalidad de no-posesión que da lugar a la organización de la nación civilizada.

\section{Neoliberalismo y Ultra-imperialismo ¿fin del ciudadano?}

El análisis del dispositivo sarmientino realizado por Scavino nos permitió poner en juego algunas hipótesis acerca del modo en que debe pensarse la lucha de clases en general y el modo en que se articula este concepto con las nociones de estado y ciudadano en particular, siempre tomando el modelo propuesto por Marín. Ahora bien, cabe preguntarse si lo que Marín vivía en 1986 es asimilable a lo que se dijo respecto de los procesos de constitución de los estados-nación: a saber, que la ciudadanización es la forma por la cual la burguesía articula su lucha de clases y que el ciudadano es el dispositivo fundamental de la fuerza social que constituye. Porque el objetivo fundamental de las dictaduras latinoamericanas a partir de Pinochet no fue otro que el de imponer un modelo neoliberal que es la última forma del imperialismo, etapa más reciente del capitalismo. ${ }^{2}$ Es claro que el neoliberalismo no hubiera podido imponerse sin previamente pasar por un proceso de desarme de las masas, desarme que fue material e intelectual. Pero el efecto de este desarme no parece ser idéntico al proceso de ciudadanización.

En un artículo de 2013, Étienne Balibar se pregunta si acaso se está asistiendo, en el actual estado del capitalismo neoliberal, al fin de "la histórica figura del 'ciudadano', el típico sujeto político y legal de la era burguesa” (2013, s/p. Traducción propia). ¿Cómo llega a esta (posible) conclusión? Balibar se pregunta por la actual hegemonía del capital financiero en el capitalismo global y sus implicancias. Si el capitalismo toma forma a partir de la aparición del estado-nación, esto implica que encuentra ahí su forma específica de reproducción. Pero esto no implica que el capitalismo no tenga una historia: se verá nacer al capitalismo de la contradicción entre capital mercantil y capital industrial, montándose el segundo sobre la extensión de la forma mercancía propiciada por el primero. Esta es, por lo menos, la versión que se encuentra en $E$ I capital de Marx y que Harvey reconstruye para nosotros (2013, p. 148):

La historia de la transición que Marx nos cuenta es esta: el capital «aparece primero en el proceso de circulación, en el que el dinero se desarrolla como capital; es en la circulación donde el producto se desarrolla por vez primera como valor de cambio, como mercancía y como dinero. El capital se puede formar en el proceso de circulación y tiene que formarse en él antes de aprender a dominar a sus extremos, las distintas esferas de producción entre las que media la circulación». Una vez que el capital ha dominado los extremos, entonces «el proceso de producción se asienta en la circulación, y esta no es más que un momento y una fase de transición de la producción» (tal como se describía en los primeros capítulos del libro segundo). Esto lleva a «la ley de que el desarrollo independiente del capital-mercancía está en proporción inversa al nivel de desarrollo de la producción capitalista». «Declina la supremacía

\footnotetext{
2 Para una definición general de neoliberalismo y su historia, ver Harvey (2007): “¿De qué modo se consumó la neoliberalización, y quién la implementó? La respuesta, en países como Chile y Argentina en la década de 1970 fue tan simple como súbita, brutal y segura, esto es, mediante un golpe militar respaldado por las clases altas tradicionales (así como también por el gobierno estadounidense), seguido de una represión salvaje de todos los vínculos de solidaridad instaurados en el seno de la fuerza de trabajo y de los movimientos sociales urbanos que tanto habían amenazado su poder." (p. 47)
} 
de pueblos puramente comerciales y de su riqueza comercial en general», lo que refleja «la subordinación del capital comercial al capital industrial» con «el desarrollo progresivo de la producción capitalista» (III-I, 432-433; KIII, 341)

Actualmente, la contradicción que resulta más patente no es aquella que opone al capital mercantil y al capital industrial, sino la contradicción entre este último y el capital financiero. Con la desaparición del estado de bienestar se ve al capital financiero comandando el proceso de reproducción y entrando en tensión con el capital industrial. Pero el capital financiero, tal como lo había analizado Marx, ha cambiado de naturaleza.

Hay dos características novedosas del régimen de acumulación del capital en su fase neoliberal. Por un lado, el capital financiero en la época de Marx se limitaba a propiciar el capital dinerario necesario para iniciar un nuevo ciclo de reproducción ampliada, por lo cual su función se limitaba a acortar el tiempo entre los ciclos y capturar la renta del capital industrial. Pero la conducción del ciclo quedaba a cargo del capitalista industrial que dirigía la inversión. Actualmente las mismas instituciones crediticias subsidian la producción y el consumo, de manera que se encuentran en ambas puntas del ciclo del capital, vendiéndose ganancias a sí mismos por intermedio de los industriales y los consumidores. Efectivamente, el capital financiero no solo opera con capitales ficticios, también "decide" los lugares y métodos de explotación. Actualmente es el capital financiero el que mide la rentabilidad de sus inversiones en cada sector, imponiendo las formas de explotación. ${ }^{3}$ Por otra parte, este sector del capital opera por toda una nueva arquitectura financiera dedicada al mercado de deudas que hunde sus raíces capilarmente en la población, sujetándola a mecanismos de crédito para cubrir sus necesidades más básicas.

Balibar, vincula ambos elementos con la globalización, que es otro nombre para el imperialismo, y afirma que en esta fase ultra-imperialista se ve con una segunda ola de proletarización. Mientras que la primera había estado ligada a la desposesión de la tierra, esta nueva ola de proletarización implica la precarización absoluta de la vida: las masas endeudadas nacen de la descomposición del ciudadano social, que en el estado de bienestar contaba entre sus derechos inalienables con ciertos servicios básicos para la vida pero que ahora deben ser cubiertos con deudas.

Pero esto implica que la naturaleza de la relación entre el estado y el capital financiero también se ha transformado. No solamente se registra una contradicción entre el carácter trasnacionalizado del capital (globalización de las cadenas de valor y creación de fondos de inversión cuyo poder económico supera el de algunos países) y el carácter nacional del poder de los estados. También sucede que el estado se convierte en un garante de deuda, transformando las deudas privadas en deudas públicas (como fue el caso durante las dictaduras latinoamericanas) y cobrándolas mediante políticas de ajuste sobre la clase trabajadora: "habiendo tomado control al mismo tiempo de los recursos del estado y de los ciudadanos, los mecanismos de crédito que concentran las deudas de todos los actores sociales se convierten en la práctica en los "reguladores" de la sociedad" (Balibar, 2013, p. s/p. Traducción propia).

Esto lleva a Balibar a hablar de una cuasi-soberanía, ya que la noción hobbesiana de soberanía como poder que no responde a ninguna autoridad se ve seriamente afectada y transformada en el marco del mercado financiero global. La soberanía de los estados se ve limitada por el capital financiero, que actúa como un pseudo-estado. Pero la soberanía del capital financiero es una cuasi-soberanía, puesto que se define negativamente como una limitación al poder de los estados sin ser él mismo una potencia político-militar. La cuestión de la soberanía y el estado lleva a la cuestión de las formas de subjetivación/ interpelación de los sujetos en la medida en que las relaciones de mercado que ligan a los sujetos individuales en la forma de contratos que los constriñen mediante deuda se convierten en una condición permanente de existencia o de no-posesión. Estas pinceladas esquemáticas parecen dar razones de peso para considerar que el modo en que las dictaduras que en el último cuarto del siglo XX impusieron un programa neoliberal mediante la guerra abierta no se ajusta del todo al esquema de Marín, puesto que antes que un proceso de ciudadanización pareciera que han abierto el terreno para la lenta disolución del ciudadano.

3 Ver Harvey (2010) El enigma del capital y las crisis del capitalismo. 


\section{Conclusiones}

La intervención de Marín permitió plantear el problema de la relación entre guerra y política a propósito de la democracia. No cualquier democracia, sino la democracia de la post-dictadura, del período posterior a la más sangrienta dictadura que se haya vivido en la Argentina y que se autodenominó "proceso de reorganización nacional". A través de la reflexión combinada de Clausewitz y Marx, Marín dio herramientas para comprender una relación íntima entre guerra y política, ya no como instancias excluyentes, sino en el modo de la subordinación de la guerra a la política: la guerra busca el desarme para imponer la voluntad política mediante el disciplinamiento de los cuerpos. La ciudadanización se mostró en este sentido como el producto específico de la lucha de clases de la burguesía durante el ascenso del capitalismo, funcionando de manera articulada con el estado-nación como forma de reproducción de la no-posesión de la clase trabajadora de la potencia de sus cuerpos, de su territorio, de sus armas, de los medios de reproducción de su vida. Las reflexiones de Scavino a propósito de Sarmiento permitieron comprender el modo en que, en la lucha de clases, como dice Althusser, lo que se enfrentan no son dos contendientes, sino dos formas de guerra, dos formas de existencia.

Si el recorrido realizado tiene sentido, es posible comprender la clave para pensar la relación entre la teoría de la guerra en Clausewitz y la ciencia de la historia fundada por Marx: en la guerra lo que se juega son las formas de flujo de los cuerpos sobre el territorio, "de ahí la importancia de conocer la estrategia del vencedor para comprender la paz que administrará: toda economía, en este sentido, es una economía de guerra". Así como hay una relación íntima entre guerra y política, también hay una relación íntima de la política con la economía. En las postrimerías de la post-dictadura también se estaba imponiendo una nueva forma de explotación del poder de los cuerpos. Esto es lo que Marín registra en su intento de pensar los efectos del concepto de lucha de clases para una teoría de la guerra y la política.

Para terminar, resulta interesante retomar una curiosa afirmación presente en el texto de Balibar que se ha comentado más arriba. Balibar se refiere a una expresión que Marx utiliza para describir las formas de explotación del trabajo asalariado y sus efectos. Marx dice que se produce un efecto de "doble molino": por un lado, la explotación sujeta a la clase trabajadora a la forma-salario como modo de reproducir su existencia. A su vez, conduce a la acumulación del producto en el polo del capitalista, quien lo transforma en capital-dinero, que redunda en la capacidad de comandar un nuevo ciclo de explotación del trabajo. De este modo, un único proceso cíclico crea las condiciones para su reiteración infinita en dos polos opuestos. Este mismo esquema se aplica, según Balibar, a la economía de la deuda en tiempos del capital financiero, produciendo la polarización entre los deudores solventes e insolventes. Estos ciclos de endeudamiento y concentración de capital también crean las condiciones para su reproducción infinita, "siempre que una nueva 'gran crisis' como la de 1929 no se produzca...” (Balibar, 2013, p. s/p. Traducción propia).

Dicha crisis, en el año 2020, ya se ha producido. La pandemia del COVID-19 no es su causa, sino solo un síntoma. Lo que resulta notable, y también insoportable, es que tome la forma de una crisis sanitaria, cuando tiene todas las características de una guerra. Los sectores populares, desposeídos de la tierra y concentrados en las periferias de las grandes urbes, mueren hacinados en habitaciones mínimas. Excluidos del campo por el capital agrario y recluidos en villas de emergencia por el capital inmobiliario, se mantienen en la alternativa de tomar por la fuerza las tierras, pero enfrentando al poder policiaco completamente desarmados, o esperar que una enfermedad que viaja a la velocidad del capital los consuma. Como conclusión de este recorrido se puede simplemente afirmar que es una buena ocasión para preguntarse, como lo había hecho Marín, acerca de las no tan claras relaciones entre guerra y política en los tiempos de la democracia de la derrota y de la mayor crisis que el capitalismo haya experimentado. 


\section{REFERENCIAS}

Althusser, L. (2019). Libro sobre el imperialismo (extractos). En, L. Althusser. Escritos sobre la historia (1963-1986), (pp. 77-183). Pólvora y Doble Ciencia

Balibar, E. (1976). Cinco ensayos de materialismo histórico. Laia

Balibar, É. (2013). Politics of debt. Postmodern culture. Journal of interdisciplinary thought on contemporary cultures, 23(3) http://www.pomoculture.org/2016/07/25/politics-of-the-debt/

Harvey, D. (2007). Breve historia del neoliberalismo. Akal

Harvey, D. (2012). El enigma del capital y las crisis en el capitalismo. Akal

Harvey, D. (2016). Guía de El capital. Libro segundo. Akal

Marín, J. C. (1987). La silla en la cabeza. Michel Foucault en una polémica acerca del poder y el saber. Nueva Americana

Marín, J. C. (2009). Cuaderno 8. Colectivo ediciones/Picaso

Marx, K. (1975). Trabajo asalariado y capital. Polémica

Piglia, R. (1980). Notas sobre Facundo. Revista Punto de Vista, (8), 15-18. http://www.bazaramericano.com/media/punto/ coleccion/revistasPDF/o8.pdf

Scavino, D. (1993). Barcos sobre la pampa. Las formas de la guerra en Sarmiento. El cielo por asalto.

\section{AUTORES}

Felipe Pereyra Rozas. Licenciado en filosofía por la Universidad Nacional de La Plata. Actualmente se encuentra desarrollando su doctorado sobre las relaciones entre sujeto, discurso e ideología en el marxismo y el pensamiento contemporáneo.

Blas Estévez. Profesor en Educación Física. Actualmente está cursando la maestría en Ciencias Sociales investigando en torno a la relación democracia-violencia-política a partir de la restauración democrática de 1983.

\section{Conflicto de intereses}

Los autores informan de ningún conflicto de interés posible.

\section{Financiamiento}

Felipe Pereyra Rozas contó con una beca doctoral otorgada por la Universidad Nacional de La Plata como asistencia financiera para la escritura del presente artículo.

\section{Agradecimientos}

$\mathrm{N} / \mathrm{A}$ 